\title{
Comparing Residential Segregation of Migrant Populations in Selected European Urban and Metropolitan Areas
}

\author{
Federico Benassi ${ }^{1}$. Corrado Bonifazi ${ }^{2} \cdot$ Frank Heins $^{2} \cdot$ Fabio Lipizzi $^{1}$. \\ Salvatore Strozza ${ }^{3}$
}

Published online: 14 July 2020

(C) The Author(s) 2020, corrected publication 2020

\begin{abstract}
Residential segregation is a well studied subject especially after the publication of the pioneering and seminal contribution of Duncan and Duncan (Am Sociol Rev 41:210-217, 1955). Considering the theoretical and methodological advances made since then, the contribution endeavours in describing and understanding the differences in residential segregation in an international perspective using 2011 population census data. The contribution analyses the residential segregation of migrants (here foreign citizens or foreign born) usually resident in the 493 Functional Urban Areas (FUAs) of selected European Union countries. The analysis is conducted using 2011 census data on regular grid $(100 \mathrm{mt} \times 100 \mathrm{mt})$ provided by the Data Challenge on 'Integration of Migrants in Cities' (D4I) and refers to all migrants and to two sub groups (EU 28 and non EU 28). In a first step the levels and spatial patterns of residential segregation across all FUAs of France, Germany, Ireland, Italy, Portugal, Spain, The Netherlands and the United Kingdom are analysed. Particular attention is paid to identifying differences and similarities between the FUAs, among and within the single countries. In a further analysis the relationship between the level of residential segregation in the metropolitan FUAs of the selected EU countries and contextual demographic and socio-economic factors are investigated. Results indicate that, even if, the larger metropolitan areas attract more migrants, the highest levels of residential segregation are observed in smaller urban areas. Moreover important national peculiarities emerge clearly with countries of northwestern Europe recording lower levels of residential segregation compared to the Southern European countries. Finally, residential segregation shows clear relationships with some contextual factors, especially the ones related to economic well-being and the labour market in a positive manner.
\end{abstract}

Keywords Residential segregation · Functional urban areas · Grid data · Migrants · Foreigners $\cdot$ Foreign born $\cdot$ Europe

Federico Benassi

benassi@istat.it

Extended author information available on the last page of the article 


\section{Introduction}

The territorial distribution of foreigners has always attracted the interest of scholars belonging to different social disciplines and stimulated special interest when leading to residential segregation. In general, residential segregation of a minority group, whether it be an ethnic group or any subgroup of the population defined socially or religiously or in other ways denotes a spatial distribution that is different from the one of the rest of the population. Although not all scholars agree on the idea that higher levels of residential segregation correspond to lower levels of integration (Portes and Zhou 1993; Musterd 2003; Bolt et al. 2010), the belief that a minority groups' residential segregation determines - at least at the macro level-a set of negative effects on the societies seems widely shared (Williams and Collins 2001; Kawachi 2002; Walton 2009; Thomas et al. 2018).

Existing international comparative studies on residential segregation of the foreign populations in the European context are numerous (Musterd 2005; Arbaci 2007; Marcińczak et al. 2016; Nielsen et al. 2017; Andersson et al. 2018a, b; Moreno-Monroy and Veneri 2018; Nieuwenhuis et al. 2020). In the European context, numerous are also studies dealing with particular territorial partitions like the analysis of Arbaci (2008) referring to Southern Europe and the contributions that address the issue of residential segregation in reference to urban Europe or specific European cities (Mustered and Ostendorf 1998; Kesteloot and Cortie 1998; Bolt 2009: Musterd and Van Kempen 2009; Tammaru et al. 2016; Musterd et al. 2017; van Ham et al. 2018; Casacchia et al. 2019). Finally, there are several individual studies that, with different approaches and at various geographical scales, address the issue of residential segregation of the foreign population with reference to individual European countries. For example: Barbagli and Pisati (2012), Mazza et al. (2018), and Benassi et al. (2019) for the Italian case, Friedrichs and Triemer (2008) and Teltemann et al. (2015) for Germany, Schönwälder and Söhn (2007), Hartog and Zorlu (2009) and Sleutjes et al. (2018) for the Netherlands, Iglesias Pascual (2017) and Rubiales Pérez et al. (2012) for Spain, Verdugo (2011) and Pan Ké Shon and Verdugo (2015) for France, Atkinson and Flint (2004) and Catney $(2016,2018)$ for the UK, Vang (2010) for Ireland. Important are also some recent studies that link residential segregation to socio-economic characteristics in different European contexts (Tammaru et al. 2016, 2020; Nieuwenhuis et al. 2020; Musterd et al. 2017).

Most of these studies use administrative divisions as primary geographical units of analysis that might be problematic for comparison purposes. Another limit is that these studies often focus on single cities as case studies without including other urban settlements and the metropolitan dimension in their analysis. Finally, they often do not refer to countries of Northern Europe and Southern Europe at the same time. This is in our view a crucial point because the Northern European countries have a longer tradition of immigration flows than the countries of Southern Europe with their more recent immigration. (Collinson 1993; de Haas et al. 2020). In addition, the Southern European countries have specific urban structures (i.e. compact cities) and less dynamic economies compared to 
Northern Europe (Kasanko et al. 2006). Moreover, whereas many studies see a clear causal link between the housing markets and the residential segregation (Arbaci 2008; Bolt et al. 2008) the relationship between residential segregation and contextual socio-economic factors is still unclear and need to be analysed more closely.

This contribution tries to overcome some of these limitations providing a comprehensive overview of the intensity, the territorial patterns and the socio-economic contextual factors of the residential segregation of migrants in the European urban space. Data used refer in fact to a regular geography (grid) allowing a robust spatial comparison between different territorial contexts such as the Functional Urban Areas (FUAs, henceforth). More in detail, the analysis refers to the EU and NonEU foreign or foreign born residents in the FUAs of 8 European countries-Italy, Portugal and Spain for Southern Europe and France, Germany, Ireland, The Netherlands and the United Kingdom for Western and Northern Europe-for a total of 493 FUAs.

The research questions underlying the study are as follows: (1) are there any differences in the levels of residential segregation between the Southern European countries (Italy, Spain and Portugal) and Northern European countries (France, Germany, Ireland, The Netherlands and the United Kingdom)?; (2) is the level of residential segregation related to the demographic dimensions of the FUAs?; (3) are there distinctive patterns of residential segregation between EU and Non-EU migrants?; (4) what are the main socio-demographic and socio-economic contextual factors that might influence the residential segregation patterns of these population groups in the major FUAs of Europe?; (5) is the higher incidence of the migrant population related to lower levels of their residential segregation?

The paper is structured as follows: in the next section statistical data and methods are described, giving particular attention to the nature of the data used and to the different national contexts studied here. The results are presented in two subsection: in the first one the levels and patterns of residential segregation and the incidence of the migrant population are presented for the FUAs analysed; in the second subsection the results of the regression analysis based on the major FUAs are presented. In the final part results are discussed and conclusions are drawn.

\section{Data and Methods}

Data used in the contribution are provided by the Data Challenge on 'Integration of Migrants in Cities' (D4I). D4I is an initiative launched at the end of 2017 by the Joint Research Center (JRC) - Knowledge Centre on Migration and Demography (KMCD) of the European Commission to disseminate to scholars and researchers a data set with population estimates for grids allowing the analysis of the concentration of migrants in selected European Union cities at high spatial resolution. ${ }^{1}$

\footnotetext{
1 Information about the D4I Data Challenge are available at this link: https://bluehub.jrc.ec.europa.eu/ datachallenge/. The main results are published in Tintori et al. 2018.
} 
This data set was produced on the basis of ad hoc extractions of the 2011 Population and Housing Census data provided by the National Statistical Institute of 8 EU member states: France, Germany, Ireland, Italy, Portugal, Spain, The Netherlands and the United Kingdom. The results of the spatial processing of the original data is an estimation of the population by place of birth or by citizenship, depending on the country, for a uniform grid (cells of 100 by 100 meters) in the countries involved in the initiative (Tintori et al. 2018). This means that data should be perfectly comparable from a geographical point of view. We refer to the JRC Technical Report (Alessandrini et al. 2017) for details about methods applied for the processing of the original data and for other technicalities regarding the estimation of the data used here.

However, it is important to underline that data stem from two different statistical concepts to reveal the origin of migrants: the country of citizenship and the country of birth. Both approaches are based on information provided by the 2011 general population censuses.

Table 1 gives an overview of the data available for the 8 European countries and offers a comparison of the data by country of citizenship and country of birth. The number of persons born abroad is generally higher, compared to the data by foreign citizenship. They reveal often the historical context of the single country. In the case of France and the United Kingdom the relatively simple rules regarding naturalization and the presence of individuals born in former colonies or areas of influence, in the case of Germany the immigration of ethnic Germans from Eastern European countries and in Spain and Italy the past of countries of emigration. Obviously the quality of the data and their content determine what the analysis will be able to reveal. For France and Italy data are available by country of citizenship, whereas for all other countries data are by country of birth. Depending on the country these two criteria, as mentioned, determine what in the present paper is defined as migrant population.

As described in detail by Alessandrini et al. (2017), the statistical information on which the estimations of the $100 \mathrm{~m}$ by $100 \mathrm{~m}$ grid data are based, in some cases refers to sample data. This occurs for technical reasons, when the original census data are based on sample techniques, or to protect the people's privacy by not communicating small case numbers. Therefore, the following analysis, wherever possible, does not refer to absolute values but only percentage values or indices and considers only broader/significant groups of the migrant population.

As already mentioned, our analysis is based on all FUAs of the countries involved in the D4I data challenge. The FUAs are functional geographical partitions proposed by OECD on the base of a defined methodology that refers to daily people's movements. In particular, FUAs are defined in order to provide a functional definition of cities and their area of influence (commuting zone), maximizing international comparability and overcoming the limitations and drawbacks of using administrative approaches ensuring, at the same time, a minimum link to the government levels of the city or metropolitan area (OECD 2012). ${ }^{2}$ In the analysis we also take into account the classification of FUAs according to population size proposed by

\footnotetext{
${ }^{2}$ About FUAs see also https://ec.europa.eu/eurostat/documents/3859598/9507230/KS-GQ-18-008-ENN.pdf/a275fd66-b56b-4ace-8666-f39754ede66b.
} 


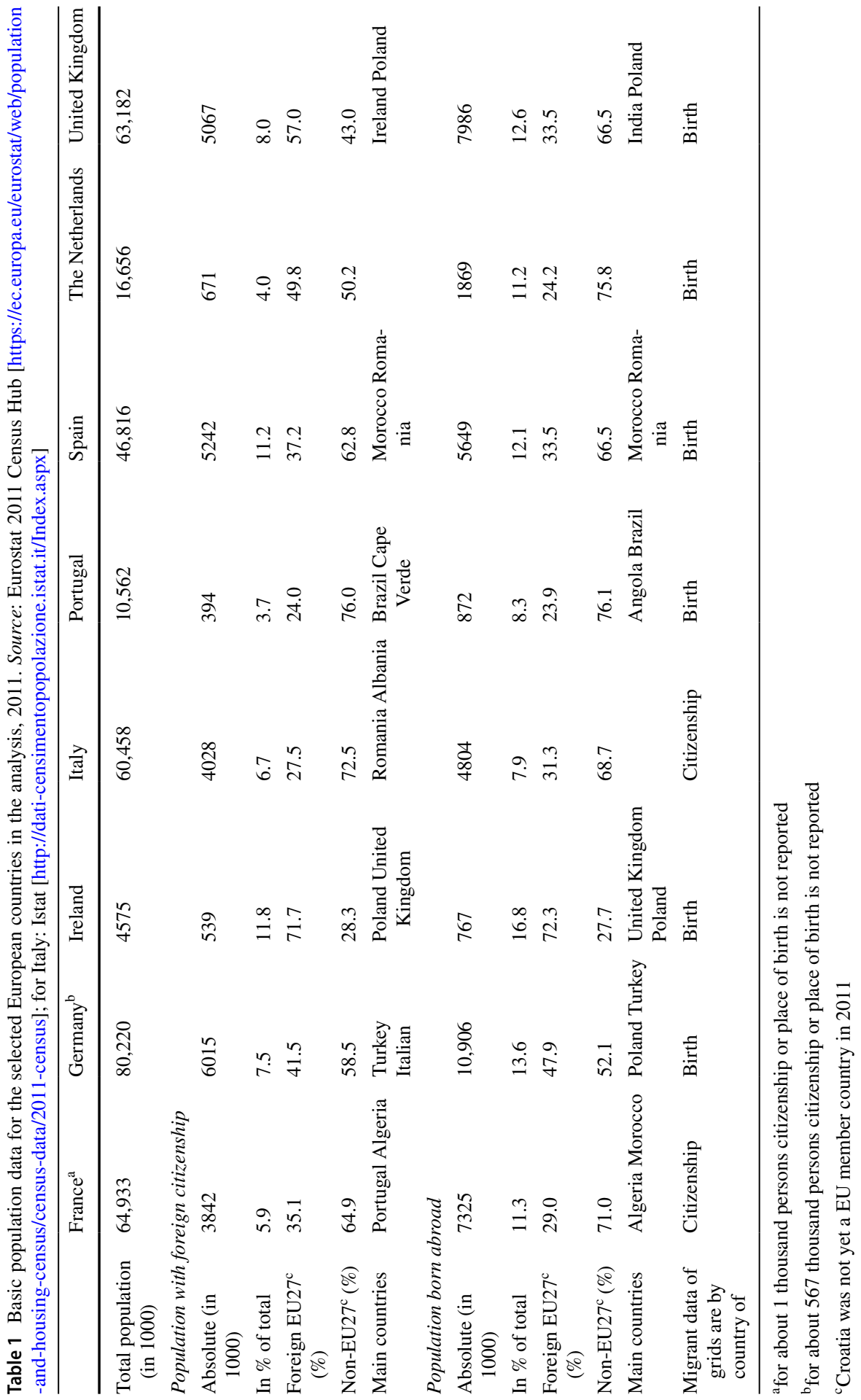


OECD and used by Eurostat in order to underline differential aspects of residential segregation within the urban and metropolitan European space. The FUAs are classified according to their demographic size into 4 categories: small urban areas (50,000-100,000 inhabitants); medium-sized urban areas (100,000-250,000 inhabitants); metropolitan areas (250,000-1.5 million inhabitants) and large metropolitan areas with more than 1.5 million inhabitants. ${ }^{3}$

The D4I data challenge (Alessandrini et al. 2017) provides grid data on population by citizenship or place of birth according by different categories: for the 'foreign EU28 countries' and 'Non-EU28 countries', for continents and for single countries. The contribution focuses on the total migrant population and the subdivision migrants from EU28 countries and from Non-EU28 countries.

The first step of our empirical analysis is for the sake of simplicity and clarity limited to two aspects of the residential segregation of migrants: the incidence of migrants and their residential segregation measured through the Index of Dissimilarity (Duncan and Duncan 1955). This analysis is carried out for the 493 FUAs of the 8 European countries studied. The Index of Dissimilarity was chosen because of its simplicity and because the grid data offer already a standardisation according to the territorial sub-division. Moreover this index has been used in several studies on residential segregation (see for example Friedman 2008; Iceland et al. 2013, 2014; Logan and Parman 2017; Malmberg et al. 2018). This part intends to answer research questions 1,2 and 3 .

In a second step an asymmetric analysis using multiple linear regression models aims at detecting potential relationships that exist between the level of residential segregation and the level of the incidence of the migrant population in the major metropolitan FUAs and some socio-economic indicators. More in detail, as 'independent' variables (i.e., contextual factors) we used a selection of socio-demographic and socio-economic indicators: population density 2011, population growth in the period 2001-2011, percentage of working age population 2011, GDP per capita and unemployment rate related to 2011. The first two variables are proxies, respectively, of the level of urbanization and of the demographic vitality of each territorial context; the percentage of working age population and the unemployment rate are linked to the local labour market situation: the first one describes the age structure and the second the dynamism of the labour market. Finally, the GDP per capita measures the economic well-being of each FUA.

The regression analysis was carried out for the entire migrant population and separately for the EU28 and Non-EU28 migrants. This analysis is limited, for practical reasons, to the metropolitan FUAs (81 FUAs) since these are the areas included in the OECD Metropolitan Database under the theme Regions and $\mathrm{Cities}^{4}$ in which demographic and socio-economic indicator are provided. The focus on the most

\footnotetext{
${ }^{3}$ Obviously each FUA presents specific urban, social and economic characteristics that are not taken into account here, except for the population size.

${ }^{4}$ Information for the metropolitan FUAs is available in the OECD Metropolitan Database https://stats .oecd.org/Index.aspx? ? Datasetcode=CITIES.
} 
populous FUAs assures also a major statistical significance of the results. This part tries to answer research questions 4 and 5.

\section{Results}

\subsection{Residential Segregation in Selected European Urban and Metropolitan FUAs}

The countries here analysed are characterized by a migrant population that often differs between countries markedly in terms of period of immigration, origins and characteristics. Germany, France and the Netherlands recorded strong immigration flows in the 1950s and 1960s, mainly from Southern European countries but, in the case of France and the Netherlands, also from their former colonies. The United Kingdom has an immigration that for a significant part comes from the Commonwealth countries. The remaining four countries have been for decades, or even centuries, areas of emigration and only in the last decades have become areas of immigration: Italy and Spain since the 1980s and more recently Portugal (from the 1990s) and Ireland (from the new millennium). It should be noted however that for Spain and Portugal the strongest immigration flows come from their former colonies (Collinson 1993; de Haas et al. 2020).

An analysis of the incidence of the migrant population and dissimilarity by size classes of FUAs reveals a significant heterogeneity but also some clear signs of regularity along the urban settlement spectrums.

Large metropolitan areas still remain the areas where the majority of foreigners reside. This is true for all the countries analysed: France $(12.9 \%$ is the value of the incidence of foreigners in large metropolitan areas vs. $10.0 \%$ in the total urban areas), Germany (17.7\% vs. $15.6 \%$ ), Italy (7.6\% vs. $7.5 \%)$, Portugal $(13.7 \%$ vs. $9.9 \%$ ), Spain (14.7\% vs. $10.8 \%$ ), The Netherlands (17.4\% vs. $13.0 \%)$, United Kingdom (24.9\% vs. $14.3 \%)$. The same pattern, with a certain degree of variability, is detected with reference to the foreign EU28 and to the Non-EU28 residents (Table 2).

The level of residential segregation of the migrant population recorded in the large metropolitan areas is in general somewhat lower than the one recorded in the total of urban areas: France (0.237 vs. 0.294), Germany (0.293 vs. 0.313), Italy (0.392 vs. 0.400$)$, Portugal (0.234 vs. 0.299$)$, Spain (0.339 vs. 0.428$)$, The Netherlands (0.385 vs. 0.413$)$, United Kingdom (0.408 vs. 0.482$)$. In Ireland the level is the same $(0.322$ and 0.321$)$. This pattern is confirmed when observing the sub-groups of migrants. Thus, even if the large metropolitan areas seem to be more attractive for migrants, we do not observe the highest levels of residential segregation in these areas, but often in the minor urban areas. However, this is not true for all countries here analyzed as the cases of Italy, Ireland and The Netherlands show (Table 2).

The lowest levels of dissimilarity (residential segregation) are observed in the large metropolitan FUAs of France and Portugal. Whereas in Portugal the levels of dissimilarity are low in all size classes, in France the level of residential segregation seems to be slightly higher in the small urban areas and lower in the large urban areas of Paris, Marseille and Lyon. On these results perhaps a bias could be ascribable to the fact 
Table 2 Incidence and indices of residential segregation of the migrant populations in the FUAs in selected countries, by population size class and by origin, 2011. Source: Authors' calculation on OECD data (https://stats.oecd.org/Index.aspx?Datasetcode=CITIES) and data provided by the European Commission in the context of the D4I data challenge (Alessandrini et al. 2017)

\begin{tabular}{|c|c|c|c|c|c|c|c|}
\hline \multirow{2}{*}{$\begin{array}{l}\text { Country } \\
\text { FUA-size class }\end{array}$} & \multirow[t]{2}{*}{ Share $(\%)$} & \multicolumn{3}{|l|}{ Incidence (\%) } & \multicolumn{3}{|c|}{ Index of Dissimilarity ${ }^{\mathrm{a}}$} \\
\hline & & All migrants & EU28 & Non-EU28 & $\begin{array}{l}\text { All } \\
\text { migrants }\end{array}$ & EU28 & Non-EU28 \\
\hline
\end{tabular}

\section{France}

\begin{tabular}{|c|c|c|c|c|c|c|c|}
\hline Small urban & 9.7 & 6.5 & 1.3 & 5.2 & 0.327 & 0.317 & 0.367 \\
\hline Medium-sized urban & 18.2 & 6.5 & 1.3 & 5.2 & 0.301 & 0.333 & 0.334 \\
\hline Metropolitan & 23.5 & 7.7 & 1.9 & 5.8 & 0.285 & 0.317 & 0.316 \\
\hline Large metropolitan & 48.6 & 12.9 & 3.1 & 9.8 & 0.237 & 0.231 & 0.286 \\
\hline Total & 100.0 & 10.0 & 2.3 & 7.7 & 0.294 & 0.303 & 0.330 \\
\hline \multicolumn{8}{|l|}{ Germany } \\
\hline Small urban & 9.7 & 13.0 & 7.3 & 5.7 & 0.314 & 0.261 & 0.476 \\
\hline Medium-sized urban & 30.2 & 14.2 & 7.0 & 7.2 & 0.324 & 0.266 & 0.447 \\
\hline Metropolitan & 28.9 & 15.6 & 7.6 & 8.0 & 0.312 & 0.254 & 0.429 \\
\hline Large metropolitan & 31.2 & 17.7 & 8.6 & 9.1 & 0.293 & 0.236 & 0.400 \\
\hline Total & 100.0 & 15.6 & 7.7 & 7.9 & 0.313 & 0.255 & 0.431 \\
\hline \multicolumn{8}{|l|}{ Ireland } \\
\hline Small urban & 18.5 & 15.9 & 11.4 & 4.5 & 0.308 & 0.285 & 0.429 \\
\hline Medium-sized urban & 14.5 & 14.8 & 10.8 & 4.0 & 0.310 & 0.304 & 0.391 \\
\hline Metropolitan & 67.0 & 18.9 & 12.0 & 6.9 & 0.322 & 0.296 & 0.413 \\
\hline Total & 100.0 & 17.7 & 11.7 & 6.0 & 0.321 & 0.296 & 0.420 \\
\hline \multicolumn{8}{|l|}{ Italy } \\
\hline Small urban & 19.0 & 7.4 & 4.3 & 3.1 & 0.374 & 0.378 & 0.483 \\
\hline Medium-sized urban & 20.5 & 8.0 & 3.9 & 4.1 & 0.419 & 0.409 & 0.512 \\
\hline Metropolitan & 15.5 & 6.4 & 2.8 & 3.6 & 0.426 & 0.442 & 0.498 \\
\hline Large metropolitan & 45.0 & 7.6 & 3.6 & 4.0 & 0.392 & 0.388 & 0.498 \\
\hline Total & 100.0 & 7.5 & 3.7 & 3.8 & 0.400 & 0.400 & 0.499 \\
\hline \multicolumn{8}{|l|}{ Portugal } \\
\hline Small urban & 15.2 & 7.9 & 2.3 & 5.6 & 0.265 & 0.261 & 0.342 \\
\hline Medium-sized urban & 10.0 & 6.1 & 2.0 & 4.2 & 0.250 & 0.259 & 0.327 \\
\hline Metropolitan & 25.3 & 4.5 & 1.0 & 3.6 & 0.247 & 0.268 & 0.271 \\
\hline Large metropolitan & 49.5 & 13.7 & 1.6 & 12.1 & 0.234 & 0.272 & 0.257 \\
\hline Total & 100.0 & 9.9 & 1.6 & 8.3 & 0.299 & 0.291 & 0.337 \\
\hline \multicolumn{8}{|l|}{ Spain } \\
\hline Small urban & 20.7 & 11.2 & 4.4 & 6.9 & 0.486 & 0.614 & 0.527 \\
\hline Medium-sized urban & 26.6 & 8.0 & 2.6 & 5.4 & 0.444 & 0.554 & 0.500 \\
\hline Metropolitan & 21.0 & 7.6 & 2.6 & 5.0 & 0.450 & 0.578 & 0.497 \\
\hline Large metropolitan & 31.6 & 14.7 & 4.3 & 10.4 & 0.339 & 0.481 & 0.379 \\
\hline Total & 100.0 & 10.8 & 3.5 & 7.3 & 0.428 & 0.553 & 0.472 \\
\hline \multicolumn{8}{|l|}{ The Netherlands } \\
\hline Small urban & 22.1 & 10.4 & 2.7 & 7.7 & 0.375 & 0.404 & 0.427 \\
\hline Medium-sized urban & 30.0 & 8.5 & 2.2 & 6.2 & 0.394 & 0.440 & 0.447 \\
\hline
\end{tabular}


Table 2 (continued)

\begin{tabular}{|c|c|c|c|c|c|c|c|}
\hline \multirow{2}{*}{$\begin{array}{l}\text { Country } \\
\text { FUA-size class }\end{array}$} & \multirow[t]{2}{*}{ Share $(\%)$} & \multicolumn{3}{|l|}{ Incidence $(\%)$} & \multicolumn{3}{|c|}{ Index of Dissimilarity ${ }^{a}$} \\
\hline & & All migrants & EU28 & Non-EU28 & $\begin{array}{l}\text { All } \\
\text { migrants }\end{array}$ & EU28 & Non-EU28 \\
\hline Metropolitan & 29.6 & 16.1 & 3.0 & 13.1 & 0.410 & 0.406 & 0.444 \\
\hline Large metropolitan & 18.2 & 17.4 & 3.4 & 14.0 & 0.385 & 0.389 & 0.420 \\
\hline Total & 100.0 & 13.0 & 2.8 & 10.1 & 0.413 & 0.415 & 0.458 \\
\hline \multicolumn{8}{|l|}{ United Kingdom } \\
\hline Small urban & 15.0 & 7.3 & 3.3 & 4.1 & 0.357 & 0.354 & 0.406 \\
\hline Medium-sized urban & 33.1 & 9.1 & 3.4 & 5.7 & 0.430 & 0.402 & 0.480 \\
\hline Metropolitan & 22.4 & 9.6 & 3.1 & 6.6 & 0.452 & 0.389 & 0.511 \\
\hline Large metropolitan & 29.5 & 24.9 & 7.4 & 17.5 & 0.408 & 0.385 & 0.432 \\
\hline Total & 100.0 & 14.3 & 4.7 & 9.6 & 0.482 & 0.432 & 0.527 \\
\hline
\end{tabular}

The Functional Urban Areas and the size classes are defined by OECD and EU (OECD 2012; http:// www.oecd.org/cfe/regional-policy/functionalurbanareasbycountry)

${ }^{\text {a }}$ The Index of Dissimilarity is computed with reference to the native population

that in France the population with French citizenship but with foreign origins is quite numerous (Tribalat et al. 1996): so the settlement geography of this acquired French population could be not really different from the one of the strictly foreign population (people with no French citizenship) and this could influence the values of the segregation measures observed. The differences in the dissimilarity index for the population size classes of the FUAs might be an indication of an important variability in the categories themselves. In fact the calculation of the index of dissimilarity for size classes is not the paramount method to present results, but serves here as a way to indicate the overall differences in the levels. Regarding the South/North European divide, the highest values of the Index of Dissimilarity are observed in Spain (except for the large urban areas) and the United Kingdom (except small urban areas). Followed by the size classes of Italy forming a compact cluster and of The Netherlands with similar levels but with important disparities regarding the incidence of the foreign born population. In Italy the incidence of persons with a foreign citizenship is similar in the size classes of the FUAs even if it is well-known that important differences between the Centrenorth and the Mezzogiorno (South and Islands) do exist. The range of values of the dissimilarity index in the case of migrant populations from a foreign EU28 country is higher compared to the case of Non-EU28 countries. The residential segregation of EU28 migrants is highest in Spain (predominantly persons born in Romania and European life-style migrants). The results for the size classes are clustered according to countries: Spain is followed, with decreasing values, by The Netherlands, Italy and the United Kingdom. France, Ireland, Portugal and Germany seem to have the lowest residential segregation in the case of EU28 migrants. It has to be underlined that the low levels in the German large metropolitan areas (Berlin, Hamburg, Munich, Cologne, Frankfurt and Stuttgart) have similar low levels, but these data do refer to the place of birth and thus include German citizens. In the case of migrants from Non-EU28 countries Spain is joined by Italy regarding the highest levels of residential segregation. 


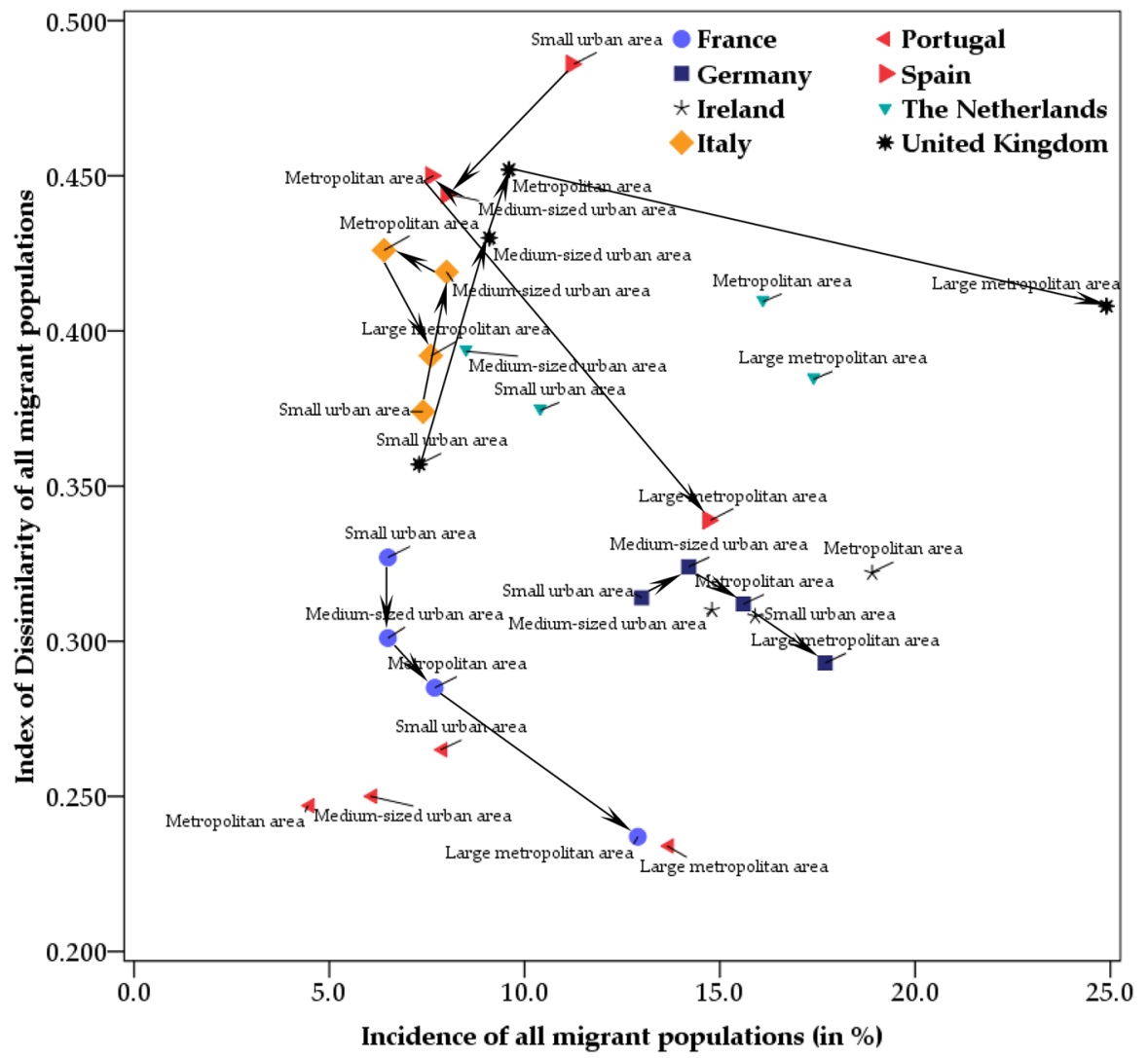

Fig. 1 Incidence and residential segregation ${ }^{(a)}$ of the migrant populations in the population size classes of the FUAs, 2011. Note: the Functional Urban Areas of France, Germany, Ireland, Italy, Portugal, Spain, The Netherlands and United Kingdom are included. Data for France and Italy refer to data by country of citizenship and in all other countries to country of birth. The Functional Urban Areas and the size classes are defined by OECD and EU (OECD 2012; http://www.oecd.org/cfe/regional-policy/functionalurban areasbycountry). Source: Authors' calculation on data provided by the European Commission in the context of the D4I data challenge (Alessandrini et al. 2017). ${ }^{(a)}$ The Index of Dissimilarity is computed in reference to the native population

It is possible that these exceptional high levels are caused by a 'hidden' heterogeneity within the two categories. The lowest levels of residential segregation of the NonEU28 migrants can be observed again in France and Portugal. The incidence of NonEU28 migrants is higher in the larger metropolitan areas, especially in the United Kingdom, followed by The Netherlands, Portugal, Spain, France and Germany.

Figure 1 substantially confirms the hypothesis that the higher incidence of foreign or foreign-born residents corresponds to lower levels of segregation (hypothesis 5), even with some exceptions, especially with reference to some large British and Dutch metropolitan areas. In general, however, what emerges is that the metropolitan areas of Southern Europe register the comparatively highest levels of residential segregation and a lower incidence of migrants. This confirms hypothesis 1 : 


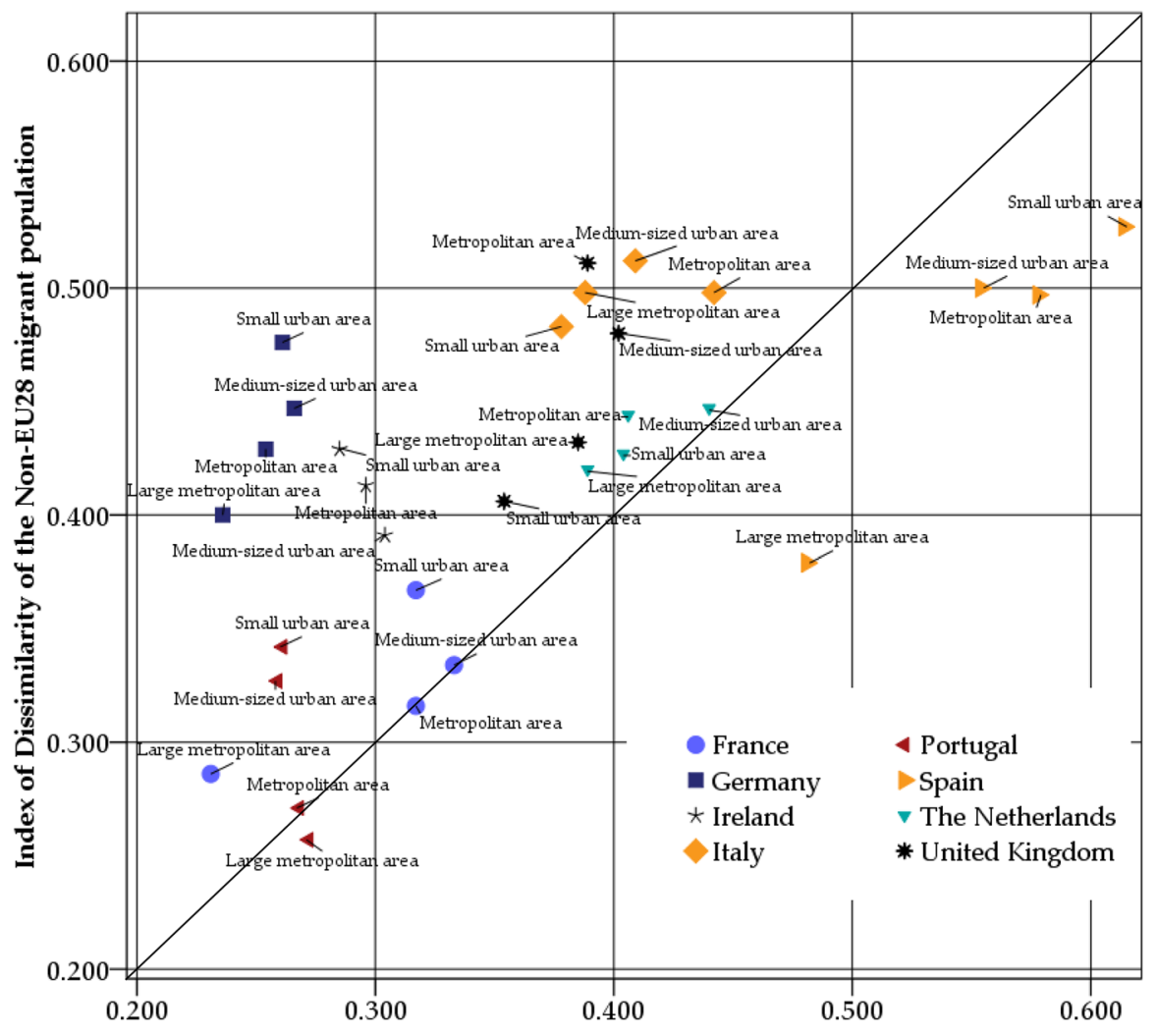

Index of Dissimilarity of the EU28 migrant population

Fig. 2 - Residential segregation ${ }^{(a)}$ of the EU28 and Non-EU28 migrant populations in the FUAs, by population size classes, 2011. Note: the Functional Urban Areas of France, Germany, Ireland, Italy, Portugal, Spain, The Netherlands and United Kingdom are included. Data for France and Italy refer to data by country of citizenship and in all other countries to country of birth. The Functional Urban Areas and the size classes are defined by OECD and EU (OECD 2012; http://www.oecd.org/cfe/regional-policy/funct ionalurbanareasbycountry) Source: Authors' calculation on data provided by the European Commission in the context of the D4I data challenge (Alessandrini et al. 2017). ${ }^{\text {(a) }}$ The Index of Dissimilarity is computed in reference to the native population

the incidence of migrant populations and their levels of their residential segregation are inversely related. The presence of foreign residents in these countries is a more recent phenomenon compared to the situation in other European countries with a longer history of immigration. When analysing the residential segregation for the size classes of FUAs, the observed values can indicate similar residential segregation in the single FUAs areas or considerable internal differences in the same population size class.

Figure 2 shows how residential segregation can probably be seen as a selective phenomenon on the basis of having a citizenship of (or being born in) a country of the European Union other than the one of residence. In general, the level of residential segregation seems to be higher for Non-EU migrants. In fact, except 

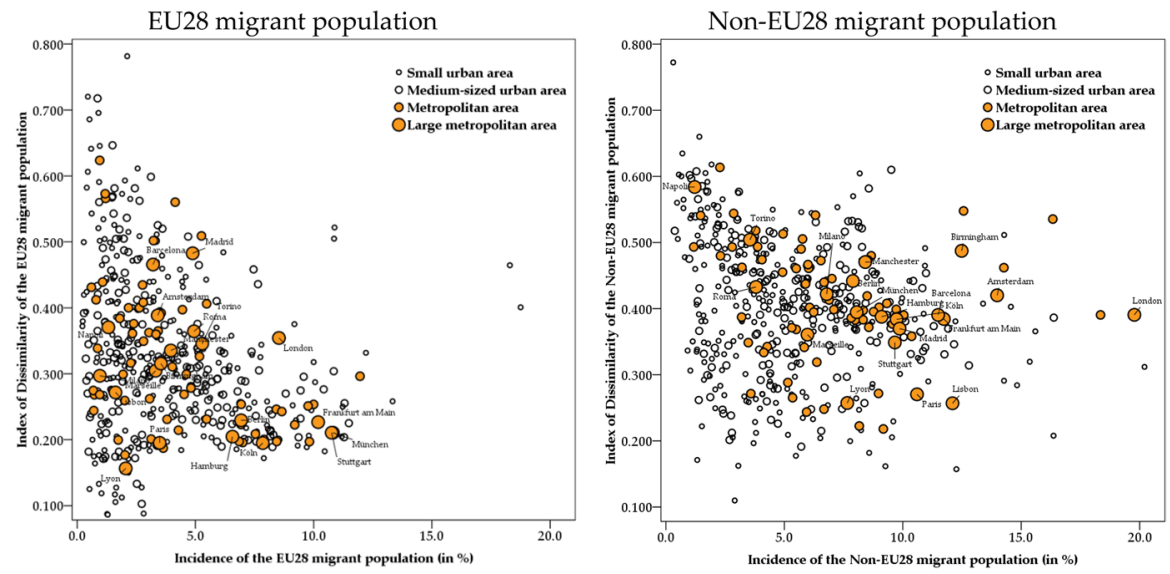

Fig. 3 Incidence and residential segregation ${ }^{(a)}$ of the EU28 and Non-EU28 migrant population in the FUAs, by population size class, 2011. Note: the Functional Urban Areas of France, Germany, Ireland, Italy, Portugal, Spain, The Netherlands and United Kingdom are included. Data for France and Italy refer to data by country of citizenship and in all other countries to country of birth. The Functional Urban Areas and the size classes are defined by OECD and EU (OECD 2012; http://www.oecd.org/cfe/regionalpolicy/functionalurbanareasbycountry). In the figure for the EU28 migrant population the FUA ES035Torrevieja is not shown, since with an incidence of $29.1 \%$ out of range. Source: Authors' calculation on data provided by the European Commission in the context of the D4I data challenge (Alessandrini et al. 2017). ${ }^{(a)}$ The Index of Dissimilarity is computed in reference to the native population

for Spain the residential segregation is systematically higher for the Non-EU28 migrants compared to the EU28 ones. The higher residential segregation for NonEU28 origin migrants observed in Germany, the metropolitan areas of the United Kingdom and most size classes of FUAs in Italy is contrasting with relative low values in Portugal and France. Nevertheless, it seems that the levels of residential segregation for the EU28 migrants and for the Non-EU28 migrants are positively related. This indicates that the factors that influence the geographic patterns of residential segregation seem to be of importance for both groups studied. However, it is known that the factors influencing the residential segregation of specific national or ethnic groups can vary significantly.

Analysing the single FUAs (Figs. 3, 4) further interesting aspects emerge. Figure 3 shows that the relationship between the incidence of migrants and the index of dissimilarity is not as linear as thought. However the variability regarding residential segregation is higher in smaller FUAs.

The patterns of the incidence of the migrant populations in the FUAs of the countries analysed confirm the findings for the population size classes even if for some countries, especially Spain, the variability between FUAs is very important and reflect in some cases specific situations: for example the FUA with the highest share of migrants born in Non-EU28 countries is Melilla (the Spanish enclave bordering Morocco). A similar high incidence have London and Den Haag. In general terms in the FUAs studied the share of Non-EU28 migrants is higher than 


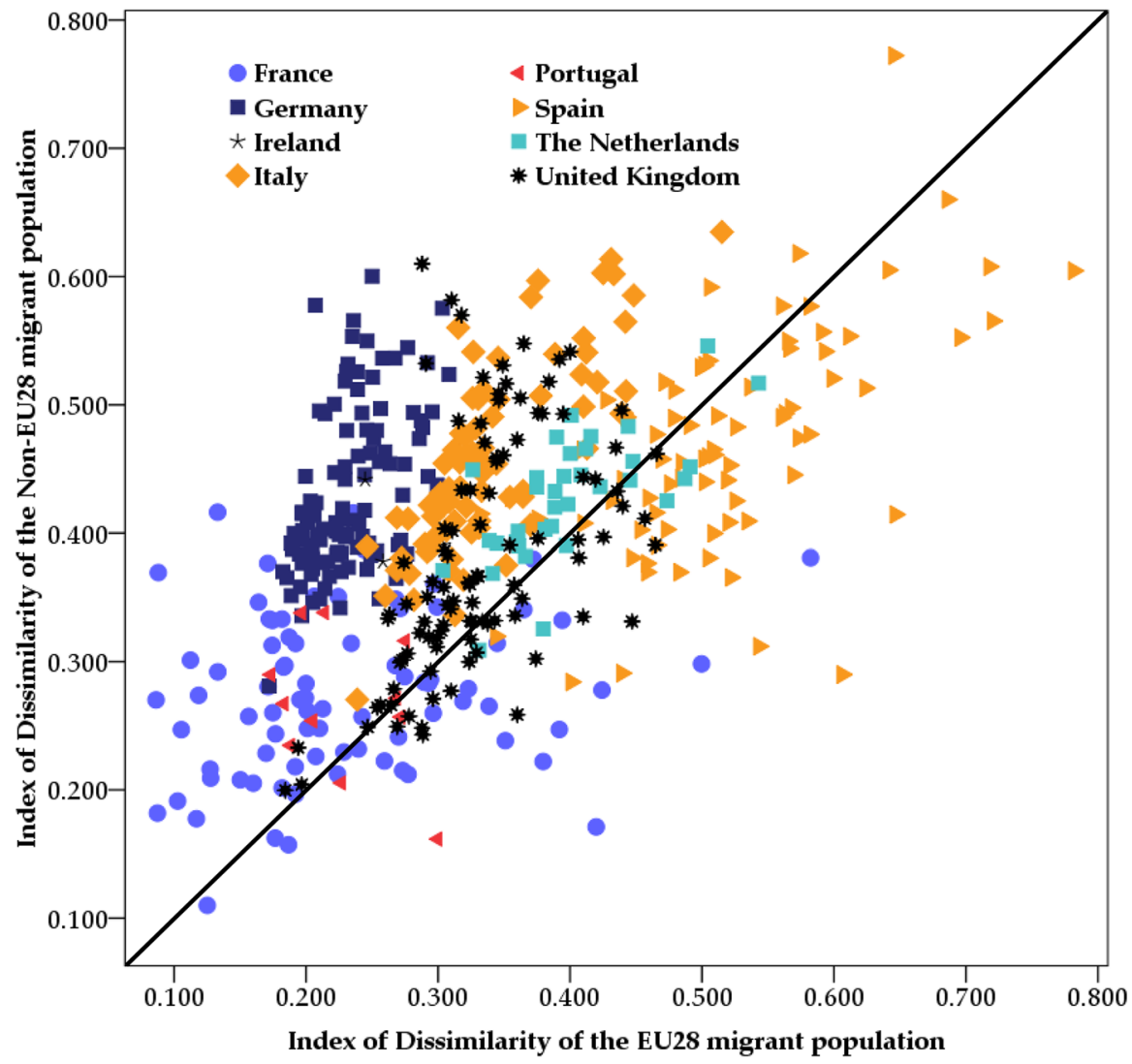

Fig. 4 Residential segregation ${ }^{(a)}$ of the EU28 and Non-EU28 migrant populations in the FUAs, by country, 2011. Note: the Functional Urban Areas of France, Germany, Ireland, Italy, Portugal, Spain, The Netherlands and United Kingdom are included. Data for France and Italy refer to data by country of citizenship and in all other countries to country of birth. The Functional Urban Areas and the size classes are defined by OECD and EU (OECD 2012; http://www.oecd.org/cfe/regional-policy/functionalurban areasbycountry). Source: Authors' calculation on data provided by the European Commission in the context of the D4I data challenge (Alessandrini et al. 2017). ${ }^{(a)}$ The Index of Dissimilarity is computed in reference to the native population

the one from EU28 countries. This was already observed at the country level with the exception of Ireland (Table 1).

Residential segregation is on the average higher for the Non-EU28 migrant population. This is especially true for the metropolitan areas of Italy, like Naples and Turin, of the United Kingdom, like Birmingham and Manchester, and of Germany, like Munich, Cologne and Frankfurt. As mentioned, residential segregation indices are generally low for the French large metropolitan areas of Lyon and Paris and also for Lisbon. The residential segregation in Madrid and Barcelona seems to be higher in the case of EU28 migrants than Non-EU28 ones. Global cities like Paris (low general level of residential segregation), London (average levels), Rome and Amsterdam 
show similar levels of residential segregation for both categories. The FUAs of the different countries appear to have their country specific position Portugal and France occupy the lower left quadrant of the graphs of Fig. 3 with dispersed values of the indices of dissimilarity, whereas the other countries appear to align in the form of rays with a steep relationship between values of the Index of Dissimilarity.

Figure 4 highlights some important points. Spain and Italy present, comparably, higher levels of residential segregation both for EU28 and Non-EU28 foreign or foreign born populations. On the opposite, the lowest levels of residential segregation are recorded in the FUAs of France. In the first case (Spain and Italy), high level of residential segregation of EU migrant populations correspond, generally, to high levels of segregation of the Non-EU28 countries ones. The same holds for France. In other countries, for example Germany, it seems that the level of residential segregation for Non-EU28 born populations is higher compared to the one of the European foreign born. The FUAs of the various countries are forming specific clusters underlining the importance of the national level in determining the level of residential segregation (and integration).

\subsection{Contextual Socio Economic Variables and Residential Segregation in the Metropolitan FUAs}

It is important to understand the relationship between the contextual factors and the residential segregation in order to provide some key elements that could be used to orient policies. In this perspective a regression analysis is carried out on the results of the major metropolitan Functional Urban Areas (FUAs) of the countries involved in the D4I data challenge.

For these 81 metropolitan FUAs additional socio-demographic and socioeconomic data are available as described in the 'Data and Methods' section. The dependent variables are the incidence of the migrant populations in the first set of model and the index of dissimilarity observed in the second set of models. The independent variables (our contextual factors) selected for the regression analysis are the population density, the population growth in the period 2001-2011, the percentage of population in working age, the GDP per capita and the unemployment rate. The analysis is carried out on the entire migrant populations, as well as on the EU28 and the Non-EU28 ones. Results are reported in Table 3.

Regarding the incidence of migrant populations, it emerges that the only negatively correlated factor is the unemployment rate: the incidence is lower where unemployment is higher. All the other independent variables are, with reference to the entire migrant populations, positively correlated with their incidence.

Differences emerge in reference to the two sub-groups, EU28 and Non-EU28 migrants, not in the direction of the relationship, but in its significance. In the first case, the EU28 migrants, only two coefficients are significant: the GDP per capita and the unemployment rate. So EU28 migrants seem to be attracted to the most dynamic areas with the higher GDP values and lower unemployment rates. On the contrary, in the second case (Non-EU28) all the correlation coefficients are significant, except for the unemployment rate, indicating that the economic situation of the FUA seems to play a less important role for this group of migrants. In this situation the overall economic situation, 
Table 3 Regression models between contextual variables and the incidence, and the residential segregation of the migrants in the major FUAs (81) of selected countries, by origin, 2011. Source: Authors' calculation on OECD data (https://stats.oecd.org/Index.aspx?Datasetcode=CITIES) and provided by the European Commission in the context of the D4I data challenge (Alessandrini et al. 2017)

\begin{tabular}{|c|c|c|c|c|c|c|}
\hline \multirow[t]{2}{*}{ Contextual variables } & \multicolumn{3}{|c|}{ Incidence (in \%) } & \multicolumn{3}{|c|}{ Index of dissimilarity ${ }^{a}$} \\
\hline & All migrants & EU28 & Non-EU28 & All migrants & EU28 & Non-EU28 \\
\hline Population density & $+0.244 *$ & -0.044 & $+0.367 * *$ & $+0.256 *$ & +0.218 & +0.140 \\
\hline Population growth (\%) & $+0.229 *$ & -0.011 & $+0.325 * *$ & +0.172 & $+0.524 * *$ & -0.152 \\
\hline $\begin{array}{l}\text { Working age popula- } \\
\text { tion }(\%)\end{array}$ & $+0.318 * *$ & +0.105 & $+0.377 * *$ & +0.166 & $+0.383 * *$ & -0.066 \\
\hline GDP per capita (US\$) & $+0.600 * *$ & $+0.547 * *$ & $+0.496 * *$ & $-0.485 * *$ & $-0.417 * *$ & $-0.517 * *$ \\
\hline $\begin{array}{l}\text { Unemployment rate } \\
(\%)\end{array}$ & $-0.339 * *$ & $-0.423 * *$ & -0.210 & $+0.363 * *$ & $+0.688 * *$ & $+0.244^{*}$ \\
\hline $\begin{array}{l}\text { Incidence }(\%) \text { by } \\
\text { country of birth or of } \\
\text { citizenship (respec- } \\
\text { tive category) }\end{array}$ & - & - & - & -0.124 & $-0.335^{* *}$ & $-0.332 * *$ \\
\hline $\begin{array}{l}\mathrm{r}^{2}(\text { Considering solely } \\
\text { the variables with } \\
\text { correlation coef- } \\
\text { ficients in bold })^{\mathrm{b}}\end{array}$ & 0.480 & 0.300 & 0.465 & 0.354 & 0.600 & 0.267 \\
\hline
\end{tabular}

Population density is measured as persons per $\mathrm{km}^{2}$ in 2011; Population growth refers to the period 20012011 in \% on a yearly basis; the Working age population is the population from 15 to 64 years in \% of the total population in 2011; GDP per capita (US\$) in 2011; Unemployment rate (\%) in 2011

Data are available for France, Germany, Ireland, Italy, Portugal, Spain, The Netherlands and the United Kingdom. Data of France and Italy refer to data by country of citizenship and to the country of birth in all other countries. The Functional Urban Areas and the size classes are defined by OECD and EU (OECD 2012; http://www.oecd.org/cfe/regional-policy/functionalurbanareasbycountry)

*Weighted correlation coefficients are significant at the 0.05 level and ** at the 0.01 level

${ }^{a}$ The Index of Dissimilarity is computed with reference to the native population

${ }^{\mathrm{b}}$ Results are of a stepwise regression analysis in which not significant variables are excluded

the degree of urbanisation and the dynamism of the areas are of higher importance than the unemployment rates. The explanatory capacity of the regression models is relatively low for all migrants with an $r^{2}$ of 0.48 . For the foreign EU28 migrant population we obtain an $r^{2}$ of 0.30 and a an $r^{2}$ of 0.47 for the Non-EU28 migrant populations.

Regarding the Index of Dissimilarity the signs of the correlation coefficients, insofar they are significant, are similar whether they refer to all migrants or to the two subgroups. This indicates that the contextual factors that affect the level of residential segregation are the same or that there is no differentiation between the two subgroups. However, the explanatory capacity of the regression models is limited with an $r^{2}$ of 0.35 for the total migrant population. It varies between a maximum $r^{2}$ of 0.60 for the foreign EU28 migrants and a very low $r^{2}$ of 0.27 in the case of the Non-EU28 migrants. In general, population density, population growth rates and unemployment rates, where significant, have a positive effect on residential segregation: that is, under the same conditions, their increase corresponds to an increase, on average, in residential segregation. The element of urbanity emerges as well as 
the importance of the labour market as factors that favour a greater integration. The GDP per capita, on the other hand, has a negative sign and therefore, where significant, acts as a deterrent to high levels of residential segregation. The incidence of the migrant population seems to be a deterrent to residential segregation showing in all cases a correlation coefficient with a negative sign, even if its influence seems to be in general limited.

Obviously these results should be read with caution: they just indicate the existence of relationships between the dependent variable-incidence and index of dissimilarity-and the contextual ones. The results cannot and should not be read or understood in terms of causality.

\section{Discussion and Conclusions}

The main findings of the study can be summarized as follows: the incidence of migrants varies considerably between countries (with the ones of Northern Europe with comparatively higher levels) and between 493 FUAs analysed. In this context, the large metropolitan areas still remain the areas with the highest share of migrant populations, confirming their attractiveness. This is true for all the countries analysed here. A similar pattern, with a certain variation, is observed for the EU28 and Non-EU28 migrants. The level of residential segregation-measured by the Index of Dissimilarity - is in most of the countries and FUAs here analysed higher for the Non-EU28 migrants. Moreover, even if the large metropolitan areas have a higher incidence, the highest levels of residential segregation are recorded in the minor urban areas. We observe a division between the 'new' immigration countries (especially Italy and Spain) and 'old' ones that record comparatively lower levels of residential segregation of migrants. The economic situation is a key dimension in the observation of residential segregation: a simple regression analysis for the metropolitan FUAs $(\mathrm{N}=81)$ shows that the level of residential segregation is positively correlated with the unemployment rate indicating that economic opportunities facilitate residential integration. Whereas higher general unemployment seems to be of less importance in the case of the incidence and the residential segregation of migrant populations, especially when their country of citizenship or birth is a Non-EU28 country. This might be an indication that these groups refer more to the informal labour market than the formal one.

The question of the integration of migrants is an important area of action especially at the local level in the EU Member states. Any political or administrative effort to improve the integration of migrants at the local level (here intended as the Functional Urban Areas) should be a well-informed effort. This contribution presents only a first analysis of the statistical data available and should be regarded as an explorative analysis. Any specific action should take into account also qualitative information regarding the specific local situation and the situation of specific migrant communities.

Further research could allow for a better aimed policy regarding the local integration of migrants taking the residential segregation of migrants as an 
indication of deficiencies regarding the efforts of their integration. Not only for residential integration of migrant populations economic development and a well functioning labour market is an important factor. The economically better off areas in general and FUAs in particular are those where a lower residential segregation is observed and where the integration of migrant populations might be easier.

The international comparison of residential segregation can have important pitfalls if statistical data and their significance are not painstakingly taken into account. Migrant data by place of birth and by citizenship are often difficult to compare. And their comparability hinges on the recent migration history of a country, or even a specific local area. When studying residential segregation, it is essential to well define the disadvantaged groups of a society or a local area and the deprived groups can vary considerably between different contexts: citizenship, place of birth, ethnic origin are all concepts that help in defining deprived groups, but very often also second and third generation migrants have to be included. Obviously also other socio-demographic characteristics might play a role in defining groups that segregate residentially.

Another point touches the size of the migrant group under investigation. The larger the migrant group the most pressing might be seen the issue of residential segregation by local administrations and policy makers.

Broader categories of migrants like EU28 and Non-EU28 origins are usually helpful in understanding overall aspects of residential migration patterns because they refer to legal aspects of migrants and their title of sojourn. However, the different countries, and in some cases ethnic groups or geographic areas of origin are usually linked to very different cultural, historical, social and economic aspects of the migration process leading to considerably different outcomes of the integration process. This outcome can be the consequence of behaviours and decisions made by the groups of migrant population and by the host societies.

Acknowledgements The authors would like to thank the organizers of the D4I Data Challenge launched in October 2017 by the Knowledge Centre on Migration and Demography (KCMD) of the European Commission's Joint Research Centre (JRC). A preliminary version of this contribution was presented at the Data Challenge on Integration of Migrants in Cities (D4I)-Final Workshop on the 27th of November 2018, in Bruxelles. The authors would like to thank G. Tintori, A. Alessandrini and F. Natale of the JRC for their support. We are very grateful to Prof. Angelo Mazza for accepting our contribution for this special issue and for advice. The comments of 3 anonymous reviewers were very helpful in improving the paper. We greatly appreciate their help. From August 2019, our activities were also part of the project "Immigration, integration, settlement. Italian-Style", funded by the Italian Ministry of University and Research (research units CNR-IRPPS and University of Naples Federico II).

\section{Compliance with Ethical Standards}

Conflict of interest On behalf of all authors, the corresponding author states that there is no conflict of interest.

Open Access This article is licensed under a Creative Commons Attribution 4.0 International License, which permits use, sharing, adaptation, distribution and reproduction in any medium or format, as long as you give appropriate credit to the original author(s) and the source, provide a link to the Creative 
Commons licence, and indicate if changes were made. The images or other third party material in this article are included in the article's Creative Commons licence, unless indicated otherwise in a credit line to the material. If material is not included in the article's Creative Commons licence and your intended use is not permitted by statutory regulation or exceeds the permitted use, you will need to obtain permission directly from the copyright holder. To view a copy of this licence, visit http://creativecommons.org/ licenses/by/4.0/.

\section{Appendix}

See Figs. 5 and 6.
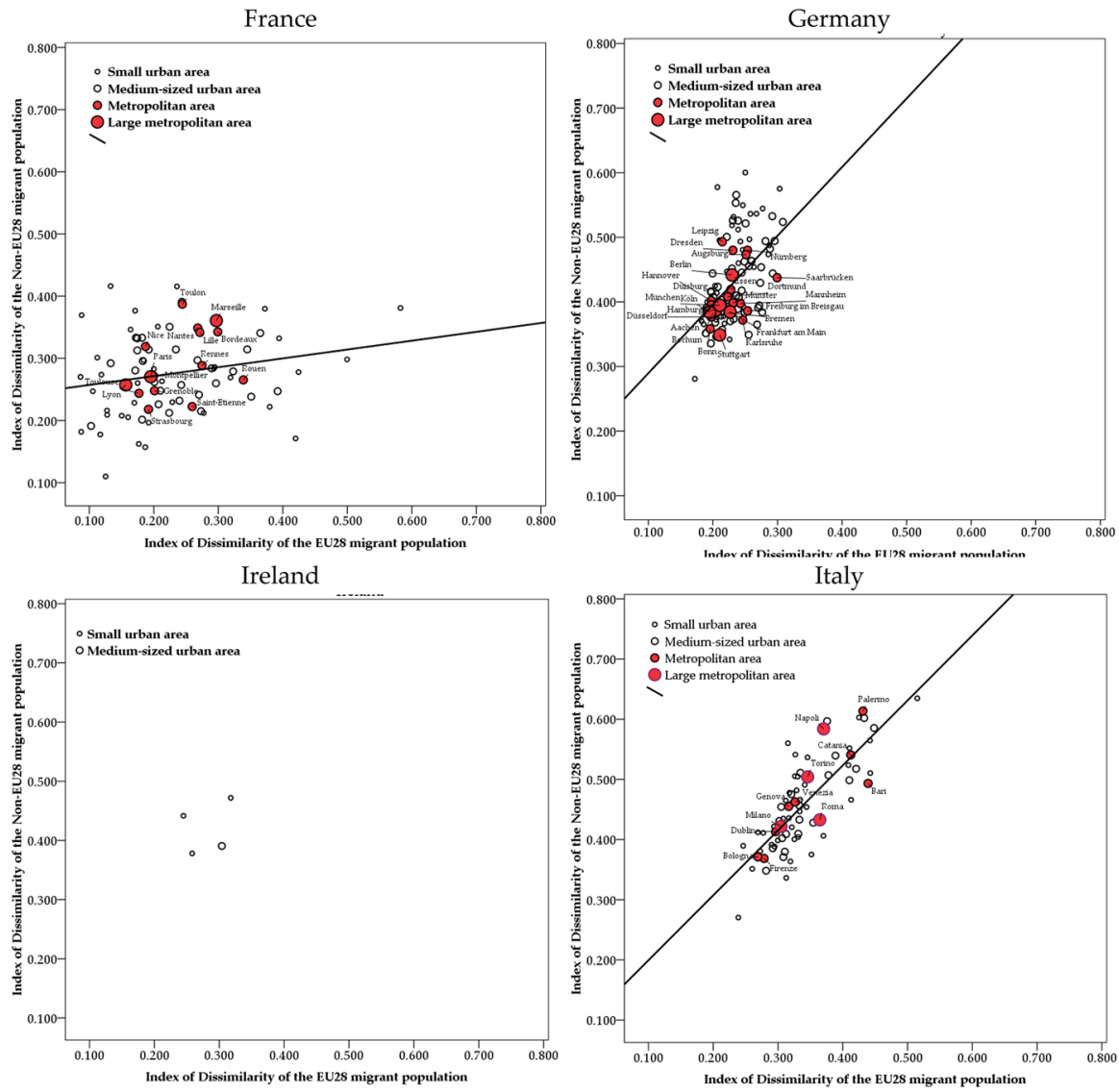

Fig. 5 Residential segregation ${ }^{(a)}$ of the EU28 and Non-EU28 migrant populations in the FUAs, by country, 2011 

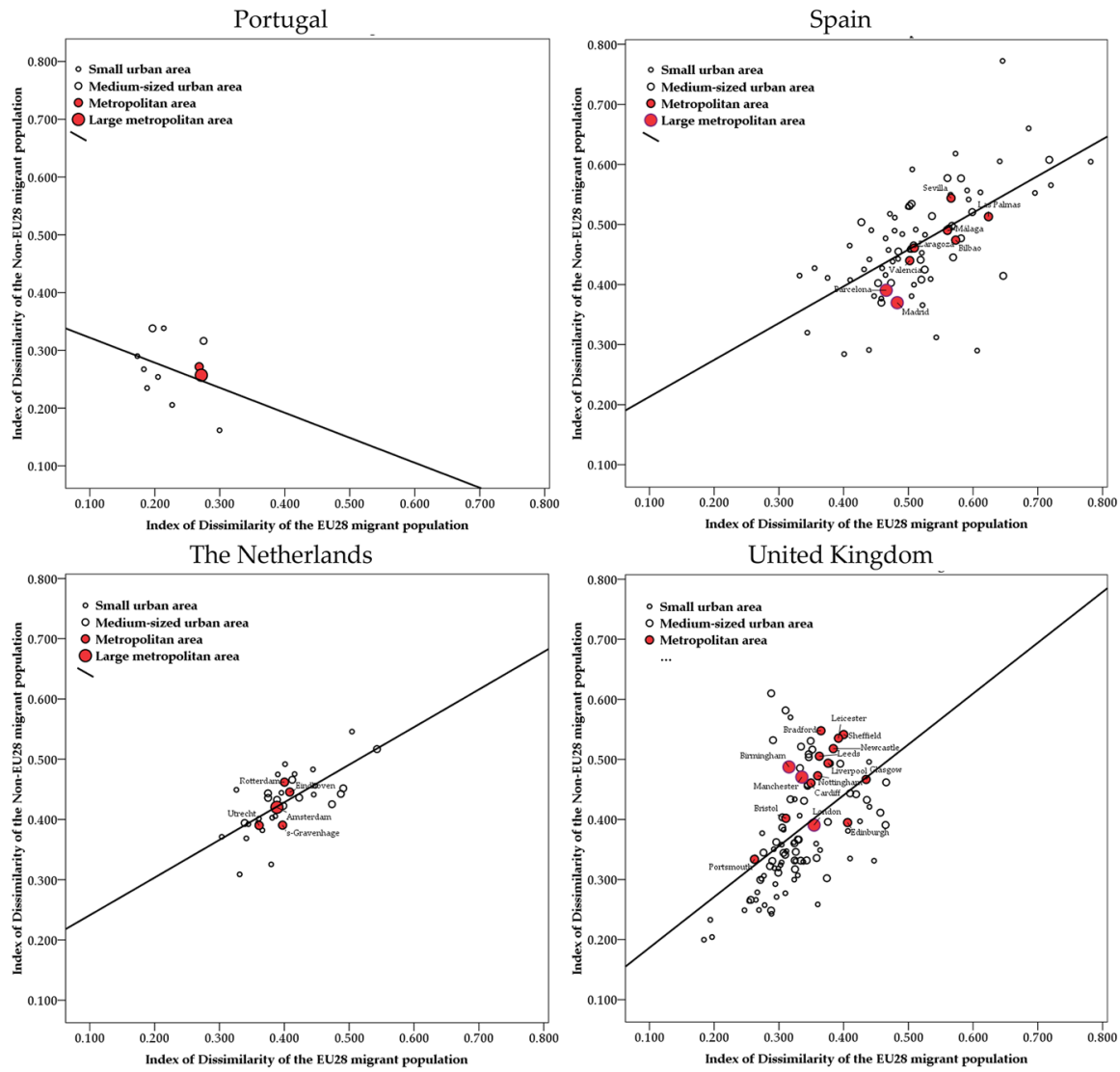

Fig. 6 Residential segregation ${ }^{(a)}$ of the EU28 and Non-EU28 migrant populations in the FUAs, by country, 2011. Note: the Functional Urban Areas of France, Germany, Ireland, Italy, Portugal, Spain, The Netherlands and United Kingdom are included. Data for France and Italy refer to data by country of citizenship and in all other countries to country of birth. The Functional Urban Areas and the size classes are defined by OECD and EU (OECD 2012; http://www.oecd.org/cfe/regional-policy/functionalurban areasbycountry). Source: Authors' calculation on data provided by the European Commission in the context of the D4I data challenge (Alessandrini et al. 2017). ${ }^{(a)}$ The Index of Dissimilarity is computed in reference to the native population

\section{References}

Alessandrini, A., Natale, F., Sermi, F., \& Vespe, M. (2017). High resolution map of migrants in the EU. JRC Technical Reports. Luxembourg: Publications Office of the European Union.

Andersson, E. K., Lyngstad, T. H., \& Sleutjes, B. (2018a). Comparing patterns of segregation in NorthWestern Europe: A multiscalar approach. European Journal of Population, 34(2), 151-168.

Andersson, E. K., Malmberg, B., Costa, R., Sleutjes, B., Stonawski, M. J., \& de Valk, H. A. G. (2018b). Comparative study of segregation patterns in Belgium, Denmark, the Netherlands and Sweden: Neighbourhood concentration and representation of non-European migrants. European Journal of Population, 34(2), 251-275.

Arbaci, S. (2007). Ethnic segregation, housing systems and welfare regimes in Europe. European Journal of Housing Policy, 7(4), 401-433. 
Arbaci, S. (2008). (Re)Viewing ethnic residential segregation in Southern European cities: Housing and urban regimes as mechanism of marginalisation. Housing Studies, 23(4), 589-613.

Atkinson, R., \& Flint, J. (2004). Fortress UK? Gated communities, the spatial revolt of the elites and time-space trajectories of segregation. Housing Studies, 19(6), 875-892.

Barbagli, M., \& Pisati, M. (2012). Dentro e fuori le mura. Città e gruppi sociali dal1 400 a oggi. Bologna: Il Mulino.

Benassi, F., Lipizzi, F., \& Strozza, S. (2019). Detecting foreigners' spatial residential patterns in urban contexts: Two tales from Italy. Applied Spatial Analysis and Policy, 12(2), 301-319.

Bolt, G. (2009). Combating residential segregation of ethnic minorities in European cities. Journal of Housing and the Built Environment, 24(4), 397-405.

Bolt, G., Özüekren, A. S., \& Phillips, D. (2010). Linking integration and residential segregation. Journal of Ethnic and Migration Studies, 36(2), 169-186.

Bolt, G., van Kempen, R., \& van Ham, M. (2008). Minority ethnic groups in the Dutch housing market: Spatial segregation, relocation dynamics and housing policy. Urban Studies, 45(7), 1359-1384.

Casacchia, O., Natale, L., \& Verdugo, G. (2019). Minority segregation processes in an urban context: A comparison between Paris and Rome Recent trends in ethnic segregation in cities: Paris and Rome compared. In C. Crocetta (Ed.), Theoretical and Applied Statistics. In Honour of Corrado Gini - SIS 2015, Treviso, Italy, September 9-11. (Springer Proceedings in Mathematics \& Statistics 274) (pp. 83-90). Cham: Springer.

Catney, G. (2016). Exploring a decade of small area ethnic (de-)segregation in England and Wales. Urban Studies, 53(8), 1691-1709.

Catney, G. (2018). The complex geographies of ethnic residential segregation: Using spatial and local measures to explore scale-dependency and spatial relationships. Transactions of the Institute of British Geographers, 43(1), 137-152.

Collinson, S. (1993). Europe and international migration. London: Pinter Publisher.

de Haas, H., Castles, S., \& Miller, M. J. (2020). The age of migration: international population movements in the modern world (6th ed.). London: Red Globe Press.

Duncan, O., \& Duncan, B. (1955). A methodological analysis of segregation indexes. American Sociological Review, 41, 210-217.

Friedman, S. (2008). Do declines in residential segregation mean stable neighborhood racial integration in metropolitan America? A research note. Social Science Research, 37(2), 920-933.

Friedrichs, J., \& Triemer, S. (2008). Gespaltene Städte? Soziale und ethnische Segregation in deutschen Großstädten. Wiesbaden: VS Verlag für Sozialwissenschaften.

Hartog, J., \& Zorlu, A. (2009). Ethnic segregation in The Netherlands: An analysis at neighbourhood level. International Journal of Manpower, 30(1-2), 15-25.

Iceland, J., Sharp, G., \& Timberlake, J. M. (2013). Sun belt rising: regional population change and the decline in black residential segregation, 1970-2009. Demography, 50(1), 97-123.

Iceland, J., Weinberg, D., \& Hughes, L. (2014). The residential segregation of detailed Hispanic and Asian groups in the United States: 1980-2010. Demographic Research, 31(20), 593-624.

Iglesias Pascual, R. (2017). Subjetividad socioespacial y gestión de la diversidad en las principales ciudades españolas. Lo que los índices de segregación no pueden reflejar. Boletín de la Asociación de Geógrafos Españoles, 75, 247-270.

Kasanko, M., Barredo, J. I., Lavalle, C., McCormick, N., Demicheli, L., Sagris, V., et al. (2006). Are European cities becoming dispersed? A comparative analysis of 15 European urban areas. Landscape and Urban Planning, 77(1-2), 111-130.

Kawachi, I. (2002). Income inequality and economic residential segregation. Journal of Epidemiological Community Health, 56, 165-166.

Kesteloot, C., \& Cortie, C. (1998). Housing Turks and Moroccans in Brussels and Amsterdam: The difference between private and public markets. Urban Studies, 35(10), 1835-1853.

Logan, T. D., \& Parman, J. M. (2017). The national rise in residential segregation. The Journal of Economic History, 77(1), 127-170.

Malmberg, B., Andersson, E. K., Nielsen, M. M., \& Haandrikman, K. (2018). Residential segregation of European and non-European migrants in Sweden: 1990-2012. European Journal of Population, 43(2), 169-193.

Marcińczak, S., Musterd, S., van Ham, M., \& Tammaru, T. (2016). Inequality and rising levels of socioeconomic segregation. Lessons from a pan-European comparative study. In T. Tammaru, M. van Ham, S. Marcińczak, \& S. Musterd (Eds.), Socio-economic segregation in European capital cities: East meets West (pp. 358-382). London: Routledge. 
Mazza, A., Gabrielli, G., \& Strozza, S. (2018). Residential segregation of foreign immigrants in Naples. Spatial Demography, 6(1), 71-87.

Moreno-Monroy, A. I., \& Veneri, P. (2018). Introduction. Divided cities: Understanding intra-urban inequalities (pp. 13-18). Paris: OECD Publishing.

Musterd, S. (2003). Segregation and integration: A contested relationship. Journal of Ethnic and Migration Studies, 29(4), 623-641.

Musterd, S. (2005). Social and ethnic segregation in Europe: Levels, causes, and effects. Journal of Urban Affairs, 27(3), 331-348.

Musterd, S., Marcińczak, S., van Ham, M., \& Tammaru, T. (2017). Socioeconomic segregation in European capital cities. Increasing separation between poor and rich. Urban Geography, 38(7), 1062-1083.

Musterd, S., \& van Kempen, R. (2009). Segregation and housing of minority ethnic groups in Western European cities. Tijdschrift Voor Economische En Sociale Geografie, 100(4), 559-566.

Mustered, S., \& Ostendorf, W. (1998). Urban segregation and the welfare state: Inequality and exclusion in western cities. London: Routledge.

Nielsen, M. M., Haandrikman, K., Christiansen, H., Costa, R., Sleutjes, B., Rogne, A., \& Stonawski, M. (2017). Residential segregation in 5 European countries. [http://docs.wixstatic.com/ugd/870ecc_d148b 555abb542d19bfcb0c1358e0f17.pdf].

Nieuwenhuis, J., Tammaru, T., van Ham, M., Hedman, L., \& Manley, D. (2020). Does segregation reduce socio-spatial mobility? Evidence from four European countries with different inequality and segregation contexts. Urban Studies, 57(1), 176-197.

OECD. (2012). Redefining urban: A new way to measure metropolitan areas. Paris: OECD.

Pan Ké Shon, J. L., \& Verdugo, G. (2015). Forty years of immigrant segregation in France, 1968-2007. How different is the new immigration? Urban Studies, 52(5), 823-840.

Portes, A., \& Zhou, M. (1993). The new second generation: segmented assimilation and its variants. The Annals of the American Academy of Political and Social Science, 530(1), 74-96.

Rubiales Pérez, M., Bayona-i-Carrasco, J., \& Pujadas Rúbies, I. (2012). Patrones espaciales de la segregación residencial en la región metropolitana de Barcelona: pautas de segregación de los grupos altos. Scripta Nova. Revista electrónica de geografiá y ciencias sociales, 16(423), 33.

Schönwälder, K., \& Söhn, J. (2007). Siedlungsstrukturen von Migrantengruppen in Deutschland: Schwerpunkte der Ansiedlung und innerstädtische Konzentrationen. WZB Discussion Paper SP IV 2007-601. Berlin: WZB.

Sleutjes, B., de Valk, H. A. G., \& Ooijevaar, J. (2018). The measurement of ethnic segregation in the Netherlands: Differences between administrative and individualized neighbourhoods. European Journal of Population, 34(2), 195-224.

Tammaru, T., Marcińczak, S., Aunap, R., van Ham, M., \& Janssen, H. (2020). Relationship between income inequality and residential segregation of socioeconomic groups. Regional Studies, 54(4), 450-461.

Tammaru, T., van Ham, M., Marcińczak, S., \& Musterd, S. (2016). Socio-economic segregation in European capital cities: East meets West. London: Routledge.

Teltemann, J., Dabrowski, S., \& Windzio, M. (2015). Räumliche Segregation von Familien mit Migrationshintergrund in deutschen Großstädten: Wie stark wirkt der sozioökonomische Status? Kölner Zeitschrift für Soziologie und Sozialpsychologie, 67(1), 83-103.

Thomas, M. E., Moye, R., Henderson, L., \& Horton, H. D. (2018). Separate and unequal: The impact of socioeconomic status, segregation, and the great recession on racial disparities in housing values. Sociology of Race and Ethnicity, 4(2), 229-244.

Tintori, G., Alessandrini, A., \& Natale, F. (2018). Diversity, residential segregation, concentration of migrants: A comparison across EU cities. JRC Technical Reports. Luxemburg: Publication Office of the European Union.

Tribalat, M., Simon, P., \& Benoît, R. (1996). De l'immigration à l'assimilation: Enquête sur les populations d'origine étrangère en France. Paris: INED.

van Ham, M., Tammaru, T., \& Jannsen, H. J. (2018). A multi-level model of vicious circles of socio-economic segregation. Divided cities: Understanding intra-urban inequalities (pp. 135-153). Paris: OECD Publishing.

Vang, Z. M. (2010). Housing supply and residential segregation in Ireland. Urban Studies, 47(14), 2983-3012.

Verdugo, G. (2011). Public housing and residential segregation of immigrants in France, 1968-1999. Population, 66(1), 169-193.

Walton, E. (2009). Residential segregation and birth weight among racial and ethnic minorities in the United States. Journal of Health and Social Behavior, 50, 427-442. 
Williams, D. R., \& Collins, C. (2001). Racial residential segregation: A fundamental cause of racial disparities in health. Public Health Reports, 116(5), 404-416.

Publisher's Note Springer Nature remains neutral with regard to jurisdictional claims in published maps and institutional affiliations.

\section{Affiliations}

\section{Federico Benassi ${ }^{1}$. Corrado Bonifazi ${ }^{2}$. Frank Heins ${ }^{2} \cdot$ Fabio Lipizzi $^{1}$. Salvatore Strozza ${ }^{3}$}

1 Italian National Institute of Statistics (Istat), Marconi Square 26/C, 00144 Rome, Italy

2 Institute for Research on Population and Social Policies (Cnr-Irpps), National Research Council, Via Palestro 32, 00185 Rome, Italy

3 Department of Political Sciences, University of Naples "Federico II", Via Leopoldo Rodinò 22, 80138 Naples, Italy 